\title{
Characteristics of Notched High Strength Materials under Tension, Torsion and Impact Loading
}

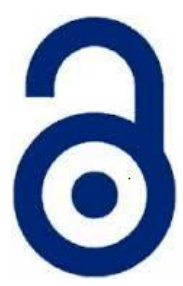 \\ Received: 12 April 2020 \\ Accepted: 09 June 2020 \\ Published: 30 July 2020 \\ Publisher: Deer Hill Publications \\ (c) 2020 The Author(s) \\ Creative Commons: CC BY 4.0
}

Abdulkareem, S., Busari, R. A., Fashola, L. A and Madu, I. A

\begin{abstract}
High carbon steel (AISI 1065) and stainless steel (AISI 304) are high strength materials that are mostly used as wear resistance materials because of their high hardness and toughness. These two materials are widely used for applications in which high strength, hardness and wear resistance are required, and these requirements are fund in cutting tools, springs and surgical instruments. Nevertheless, the presence of notch in these materials do affect their service life. This paper reports on the characteristics of notched high carbon steel and stainless steel materials investigated under tensile, torsion and impact loads. The behaviour of the materials was examined under different notch parameters of angle $30^{\circ}, 45^{\circ}$ and $60^{\circ}$ and notch base radius of $0.5 \mathrm{~mm}$ and $1.0 \mathrm{~mm}$. The tensile, torsion and impact test samples were prepared according to ASTM E8M, ASTM F383-15 and ASTM E23-16b respectively. Examination on the tensile and torsion tests were carried out on Testometric Universal Testing Machine (TUTM), while Avery-Denison Izod impact testing machine was used for impact test. The results obtained for the two materials showed that there is increase in absorption energy and resistance to twisting failure as notch tip radius and notch angle increase.
\end{abstract}

Keywords: Hardened steels, Notch parameters, Mechanical properties.

\section{INTRODUCTION}

High carbon (AISI 1065) and stainless steels (AISI 304) are two types of materials widely used for applications in which high strength, hardness and wear resistance are required particularly in tools steel, dies, cutting tools, springs in manufacturing and automobile industries as well as surgical instruments in medical industries [1-3]. The performance of these material during their service life depends on inherent properties of the materials, loading system, maintenance culture and environmental effects. These factors can be attributed basically to either the design, manufacturing deficiencies and or handling issue [4]. Hence, presence of notch which affect the performance of most materials irrespective of their service or loading conditions could be as a result of design/manufacturing problem or handling issue $([5-6]$.

Most engineering components and structures do have notch of various shapes which could be in the form of $V$ shape threads on bolts, surface scratches, key ways grooves on shafts, non-metallic inclusions and corners, fillets and discontinuities in geometrical shapes, cracks in smooth structural components such as round bars, pipes and shells [79]. Stress developed by notch of any form do influence the behaviour of materials and the study of notch properties of materials provides information regarding the effects of stress concentrations of varying magnitude which also helps to understanding how stresses influence material performance under service [10-11].

Many research works among whom are [12-22], Kobayashi et al, 2019; Naqiuddin et al, 2017; Nath \& Das, 2006; Rittel et al, 2014; Rozumek et al, 2006; Tlilan et al, 2006; Tlilan, et al 2005; Todkari et al, 2015; Zappalorto \& Lazzarin, 2011; Zehsaz et al, 2010; Zhao et al, 2019 have been documented on the effects of notch on materials behaviour. However, documented work on high strength materials such as high carbon (AISI 1065) and stainless steels (AISI 304) are rarely available.

Hence, the objective of this work is to examine the characteristics of the two high strength steels (high carbon steel and stainless steel) under tensile, torsion and impact loading conditions. The behaviour of the materials were examined under $V$-shaped notch geometry of different notch parameters of angle $30^{\circ}, 45^{\circ}$ and $60^{\circ}$ and notch base radius of $0.5 \mathrm{~mm}$ and $1.0 \mathrm{~mm}$.

S. Abdulkareem $\bowtie$, R. A. Busari, L. A. Fashola and I. A. Madu

Department of Mechanical Engineering,

Faculty of Engineering and Technology,

P.M.B. 1515, University of Ilorin, Nigeria.

E-mail: sulkarm@yahoo.com

Reference: Abdulkareem, S., Busari, R. A., Fashola, L. A and Madu, I. A. (2020). Characteristics of Notched High Strength Materials under Tension, Torsion and Impact Loading. International Journal of Engineering Materials and Manufacture, 5(3), 68-75. 


\section{MATERIALS, EQUIPMENT AND SAMPLES PREPARATION}

\subsection{Materials and Equipment}

The materials used in the study were high carbon steel (AISI 1065) and austenitic stainless steel (AISI 304), while the equipment employed in the work were spectrometer model AFS 200T, Testometric Universal Testing Machine (UTM) model FS-50AT and Avery-Denison lzod impact testing machine.

\subsection{Samples Preparation}

Samples were prepared from high carbon steel (AISI 1065) and austenitic stainless steel (AISI 304) materials. The chemical compositions of the high carbon steel and stainless steel materials used as shown in Tables 1 and 2 respectively were determined using spectrometer model AFS 200T.

The tensile test samples were prepared based on ASTM E8M-16 [23], with gauge length of $55 \mathrm{~mm}$ and radius of $5 \mathrm{~mm}$. The test was carried out on Testometric Universal Testing Machine (UTM) model FS-50AT with maximum load capacity of 50KN. According to ASTM F383-15 [24], the Torsion test was carried out on sample length of 144 $\mathrm{mm}$, gauge length of $36 \mathrm{~mm}$ and radius of $5 \mathrm{~mm}$ with the same notch parameters as that of Tensile test.

The impact test according to ASTM E23-16b [25] was carried out on an Avery-Denison Izod impact testing machine. The samples were prepared with gauge length of $55 \mathrm{~mm}$, diameter of $10 \mathrm{~mm}$, and notch tip radii of $0.5 \mathrm{~mm}$ and $1.0 \mathrm{~mm}$ with notch angles of $30^{\circ}, 45^{\circ}$ and $60^{\circ}$ on the two steel samples. A Peripheral $30^{\circ}, 45^{\circ}$ and $60^{\circ} \mathrm{V}$-notch were in turn prepared at the center of gauge length of all the samples. The schematic of the impact test sample is shown in Figure 1.

Table 1: Chemical composition of the high carbon steel (AISI 1065).

\begin{tabular}{cccccccccc}
\hline $\mathrm{C}$ & $\mathrm{Si}$ & $\mathrm{Mn}$ & $\mathrm{S}$ & $\mathrm{P}$ & $\mathrm{Cr}$ & $\mathrm{Mo}$ & $\mathrm{Ni}$ & $\mathrm{Cu}$ & $\mathrm{Fe}$ \\
\hline 0.652 & 0.77 & 0.732 & 0.043 & 0.31 & 0.071 & 0.052 & 0.139 & 0.053 & Balance \\
\hline \multicolumn{8}{c}{ Table 2: Chemical composition of the stainless (AISI 304) } & steel. \\
\hline $\mathrm{Cr}$ & $\mathrm{Ni}$ & $\mathrm{Mn}$ & $\mathrm{Si}$ & $\mathrm{C}$ & $\mathrm{P}$ & $\mathrm{S}$ & $\mathrm{Fe}$ \\
\hline 18.21 & 8.35 & 1.31 & 0.53 & 0.06 & 0.075 & 0.019 & Balance \\
\hline
\end{tabular}

\subsection{Notching of Materials}

Samples for the two materials (AISI 1065 and AISI 304 stainless steel) were prepared for lzod impact test with circular cross-section and contains $30^{\circ}, 45^{\circ}$ and $60^{\circ} \mathrm{V}$-notch, $2 \mathrm{~mm}$ deep with a $0.5 \mathrm{~mm}$ and $1.0 \mathrm{~mm}$ root radius for each sample (Fig. 1). The samples were supported as overhanging vertical beam and loaded in the front of the notch using swinging pendulum.

\subsection{Tensile Test Sample}

Computerized tensile testing machine was used for this experiment. The samples in accordance to ASTM [23], were prepared according to ASTM standards (Fig. 2). Tensile force was applied until the sample reached its failure point. The stress-strain relationship parameters for each of the sample were obtained and recorded.

\subsection{Torsion Test}

The samples were gripped onto the torsion testing machine using hexagonal sockets and was firmly mounted. Both ends of the sample were fitted to input and torque shafts and reading on the torque meter was set to zero. Twisting the sample at strain increment of 0.5 was made until failure occurs. Average of three readings were taken for the torsion tests carried out on Testometric Universal Testing Machine (TUTM, model: FS-50AT).

\subsection{Impact Test}

Izod impact testing machine (Model: 067/05-U-33122) was used for the test. The arm of the machine was allowed to swing freely to ensure freedom of movement of the striker. Each sample was clamped to the anvil and rigidly tightened by lever at the base of the machine. The pointer was set to zero-energy position and the striker released from a fixed height throughout the procedure. The average of the three energy values absorbed by each sample as indicated by the loose registering pointer on scale were record.

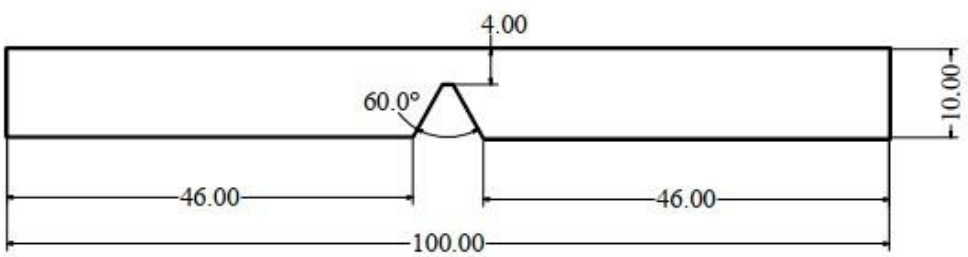

Figure 1: Schematic of notched sample 


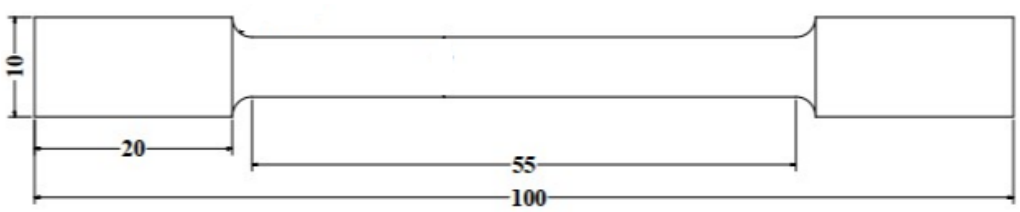

Figure 2: Sample for the tensile test.

\section{RESULTS AND DISCUSSION}

T3.1 Tensile Test Result for the AlSI 1065 Steel (HCS)

The result of the tensile test for the HCS is shown in Table 3. The recorded values of yield strength and ultimate tensile strength for the three notch angles $\left(30^{\circ}, 45^{\circ}\right.$ and $\left.60^{\circ}\right)$ is higher for $0.5 \mathrm{~mm}$ notch radius than the values obtained for $1.0 \mathrm{~mm}$ notch radius. This observation is not unconnected to the reduction in effective area that come to play at the point of loading during the application of force.

The result of the UTS for the HCS (Table 3) follows the same trend with the result obtained for the yield strength, with the highest ultimate tensile strength of $1622.107 \mathrm{~N} / \mathrm{mm} 2$ recorded for $0.5 \mathrm{~mm}$ notch radius placed at $45^{\circ}$ on the sample. The next to this is $1569.471 \mathrm{~N} / \mathrm{mm} 2$ UTS values recorded for notch tip radius of $1 \mathrm{~mm}$ at $45^{\circ}$. On the other hand, the results of the percentage elongation (Table 3) for the $1.0 \mathrm{~mm}$ notch radius is higher than that obtained for $0.5 \mathrm{~mm}$ notch radius for all the three angles $\left(30^{\circ}, 45^{\circ}\right.$ and $\left.60^{\circ}\right)$ used in the work.

The highest elongation of $8.167 \%$ was recorded for notch radius of $1.0 \mathrm{~mm}$ placed at $45^{\circ}$. It is expected that the highest elongation will result in highest UTS values in the sample, since the highest value of elongation would subject the material to experience more (high) tensile strength before crack initiation which will eventually lead to fracture could occur in the material. However, the occurrence of $1622.107 \mathrm{~N} / \mathrm{mm} 2$ values of UTS at 450 could be as a result of presence of high stress raiser at base of at 450 angle. The plots of stress versus strain at 450 with 0.5 and $1.0 \mathrm{~mm}$ radius that give the highest yield and ultimate tensile strength are shown in Figure. 3.

It can be observed from Fig. 3 that the HCS display less ductility as compare to the stainless steel because of the presence of high percentage carbon content. The effect of the carbon contents in HCS could have a significant impact in the fracture of the materials since high carbon contents increases the hardness of the material which may likely make the material stronger thereby resulting in high ultimate tensile strength. It was noticed that failure of the sample occurs at the notched point due to tensile loading, this occur because of higher stress concentration at the notched point.

Table 3: Tensile test result for AISI 1065 steel (HCS)

\begin{tabular}{|c|c|c|c|c|c|c|}
\hline & $30^{\circ}$ & & $45^{\circ}$ & & $60^{\circ}$ & \\
\hline & $0.5 \mathrm{~mm}$ & $1.0 \mathrm{~mm}$ & $0.5 \mathrm{~mm}$ & $1.0 \mathrm{~mm}$ & $0.5 \mathrm{~mm}$ & $1.0 \mathrm{~mm}$ \\
\hline Yield strength $\left(\mathrm{N} / \mathrm{mm}^{2}\right)$ & 1150.321 & 1035.677 & 1522.107 & 1469.471 & 1253.784 & 1143.064 \\
\hline UTS $\left(\mathrm{N} / \mathrm{mm}^{2}\right)$ & 1250.474 & 1182.381 & 1622.107 & 1569.471 & 1353.784 & 1243.064 \\
\hline Elongation (\%) & 5.441 & 5.936 & 7.013 & 8.167 & 5.100 & 6.282 \\
\hline
\end{tabular}

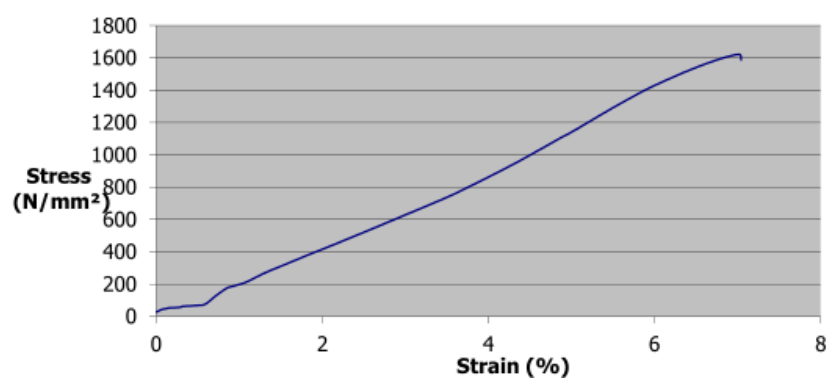

(a)

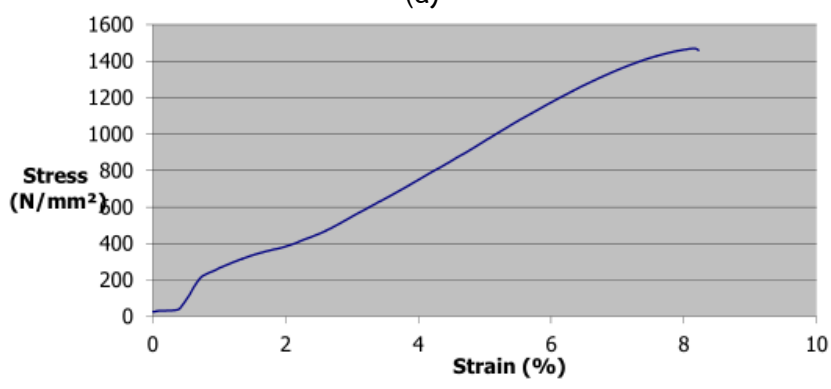

(b)

Figure 3: Stress against strain of HCS at $45^{\circ}$ notch angle and (a) $0.5 \mathrm{~mm}$, (b) $1.0 \mathrm{~mm}$ tip radius 


\subsection{Tensile Test Result for the AISI 304 (Stainless Steel)}

Table 4 shows the Tensile result for stainless steel (AISI 304) samples. The highest yield strength of $1788.293 \mathrm{~N} / \mathrm{mm} 2$ was recorded with notch radius of $1.0 \mathrm{~mm}$ placed at $60^{\circ}$ on the sample, while the corresponding highest ultimate tensile strength of $2028.525 \mathrm{~N} / \mathrm{mm} 2$ was recorded with the same notch parameter. Contrary to the results of tensile test and ultimate tensile strength obtained for the HCS (Table 4), the results of yield strength and ultimate tensile strength recorded for stainless steel (AISI 304) is higher for $1.0 \mathrm{~mm}$ notch radius than the values obtained for $0.5 \mathrm{~mm}$ notch radius for the three notch angles of $30^{\circ}, 45^{\circ}$ and $60^{\circ}$. The highest percentage elongation of $7.702 \%$ was recorded at $60^{\circ}$ notch angle with $1.0 \mathrm{~mm}$ radius. The behaviour of stainless steel at elevated temperature (strain hardening in this case) whereby the steel resist loading action resulting in higher elongation before fracture. Furthermore, the $60^{\circ}$ and $1.0 \mathrm{~mm}$ notch parameters which give high notch angles and tips radius have the high absorption energy due to the fact that the sample has more area at the root tip which is likely not be easy for crack to be initiated and when eventually it is initiated, the crack will cover a large area before the material is fracture, hence results in higher absorbed energy. The plots of stress against strain at $60^{\circ}$ notch angle with 0.5 and $1.0 \mathrm{~mm}$ radii that give the highest ultimate tensile strength are shown in Figure 4, it can be observed from Figure. 4 that the stainless steel (AISI 304) sample display better ductility property before fracture as against the HCS sample.

Table 4: Tensile test result for AISI 304 steel (Stainless Steel)

\begin{tabular}{lrrrrrr}
\hline & \multicolumn{1}{l}{$30^{\circ}$} & \multicolumn{4}{l}{$45^{\circ}$} & \multicolumn{6}{c}{$60^{\circ}$} \\
\hline & $0.5 \mathrm{~mm}$ & $1.0 \mathrm{~mm}$ & $0.5 \mathrm{~mm}$ & $1.0 \mathrm{~mm}$ & $0.5 \mathrm{~mm}$ & $1.0 \mathrm{~mm}$ \\
Yield strength & 1450.121 & 1697.129 & 1567.259 & 1741.947 & 1486.281 & 1788.293 \\
$\left(\mathrm{~N} / \mathrm{mm}^{2}\right)$ & & & & & & \\
UTS $\left(\mathrm{N} / \mathrm{mm}^{2}\right)$ & 1690.353 & 1937.361 & 1807.491 & 1982.179 & 1726.513 & 2028.525 \\
Elongation (\%) & 5.158 & 6.017 & 7.417 & 7.567 & 6.536 & 7.702 \\
\hline
\end{tabular}

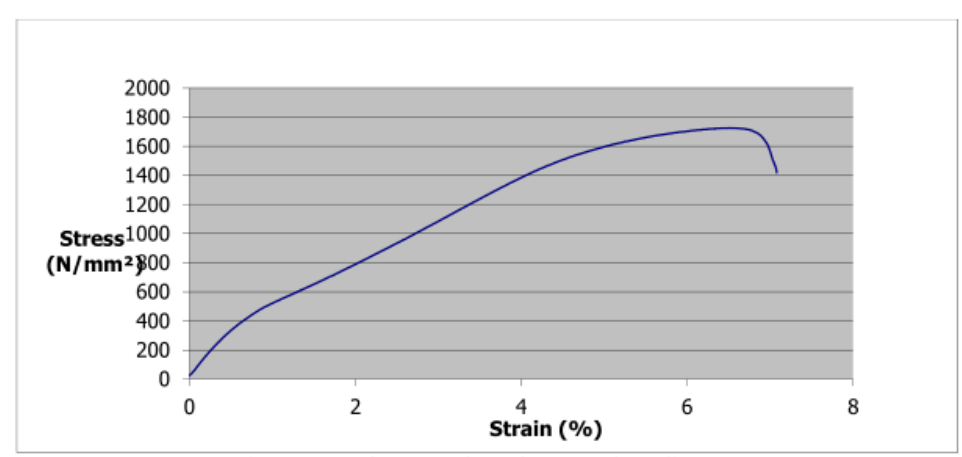

(a)

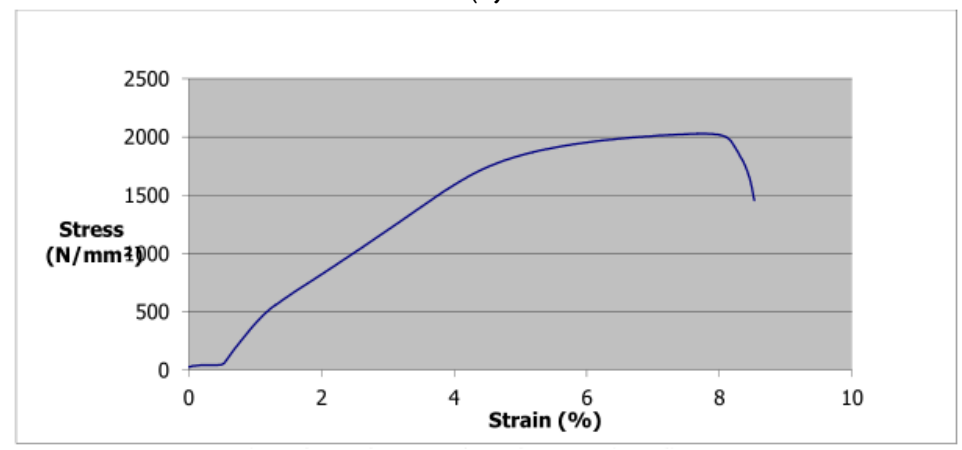

(b)

Figure 4: Stress against strain for Stainless Steel at $60^{\circ}$ notch angle and (a) $0.5 \mathrm{~mm}$, (b) 1.0 notch tip radius

\subsection{Torsion Test}

The results of the torsion tests for the samples of AISI 1065 and AISI 304 steels are shown in Figures 5 and 6. It can be observed (Figures 5 and 6) that the effect of notch radius does not have a significant difference as the values obtained for the 0.5 and $1.0 \mathrm{~mm}$ radii are very close for the two materials. The torsion results for the two materials show that as notch angle increase with notch tip radius, the higher the torque required to twist the steels. The larger the notch angle and tip radius, the higher the torque that is required to twist the steel, this simply means that lower notch tips radius and smaller notch angle will have low resistance to twisting forces due to the fact that the sample has smaller area at the root tip which makes it easier for the crack to be initiated unlike that of larger tip radius and larger notch angle where the crack initiation has larger area to contend with, before it can be initiated hence results to more resistance to twisting. 


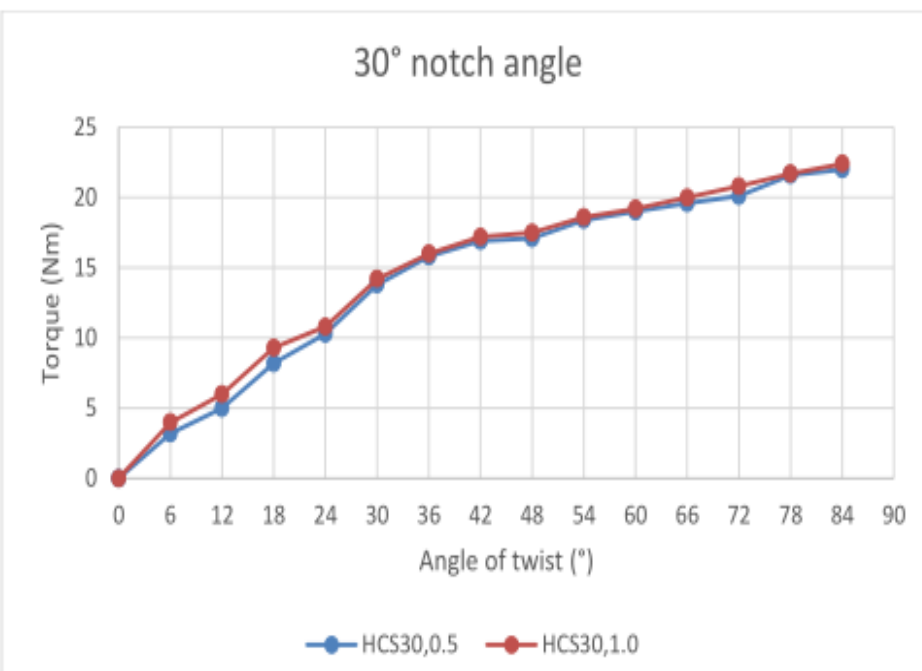

(a) $\mathrm{HCS}$ at $30^{\circ}$ notch angle, $0.5 \mathrm{~mm}$ and $1.0 \mathrm{~mm}$ notch radius

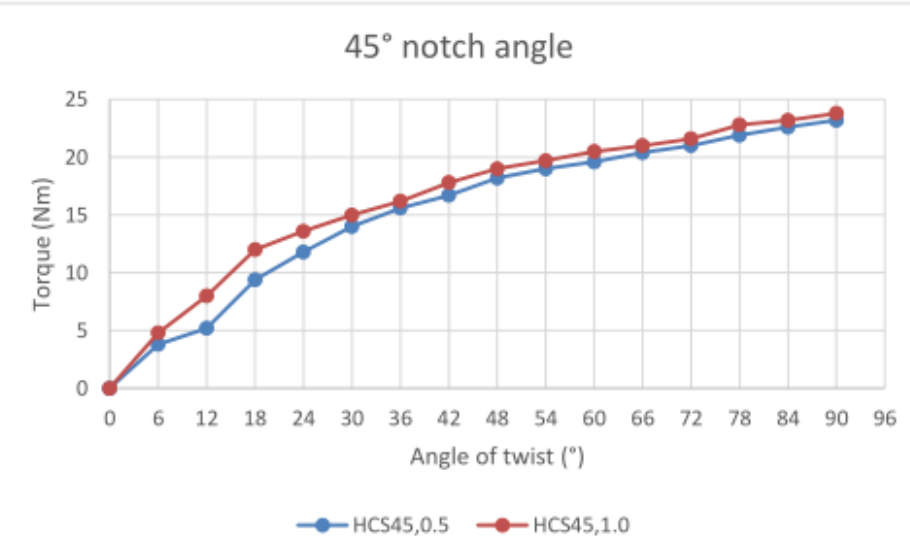

(b) $\mathrm{HCS}$ at $45^{\circ}$ notch angle, $0.5 \mathrm{~mm}$ and $1.0 \mathrm{~mm}$ notch radius

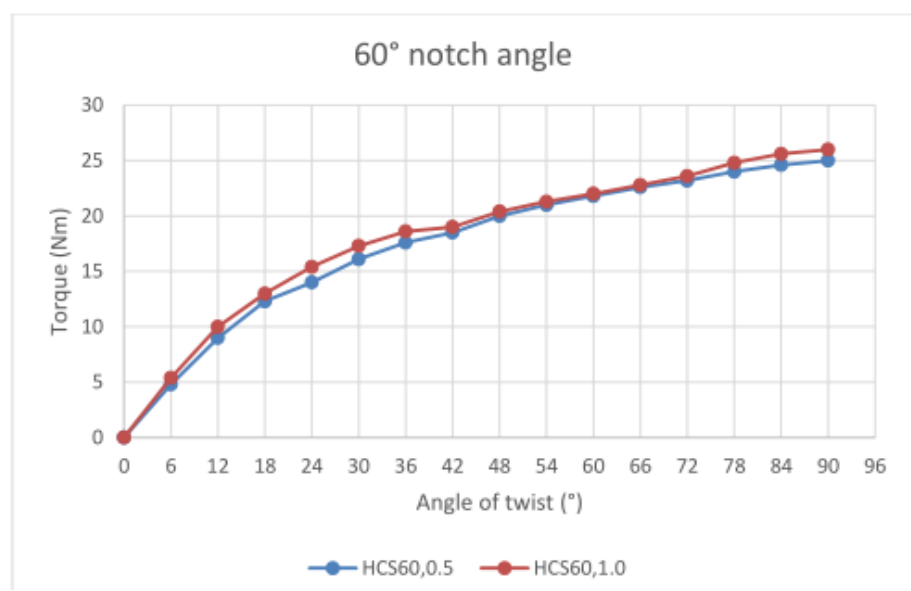

(c) $\mathrm{HCS}$ at $60^{\circ}$ notch angle, $0.5 \mathrm{~mm}$ and $1.0 \mathrm{~mm}$ notch radius

Figure 5: Effect of notch parameters on AISI 1065 steel (HCS) 


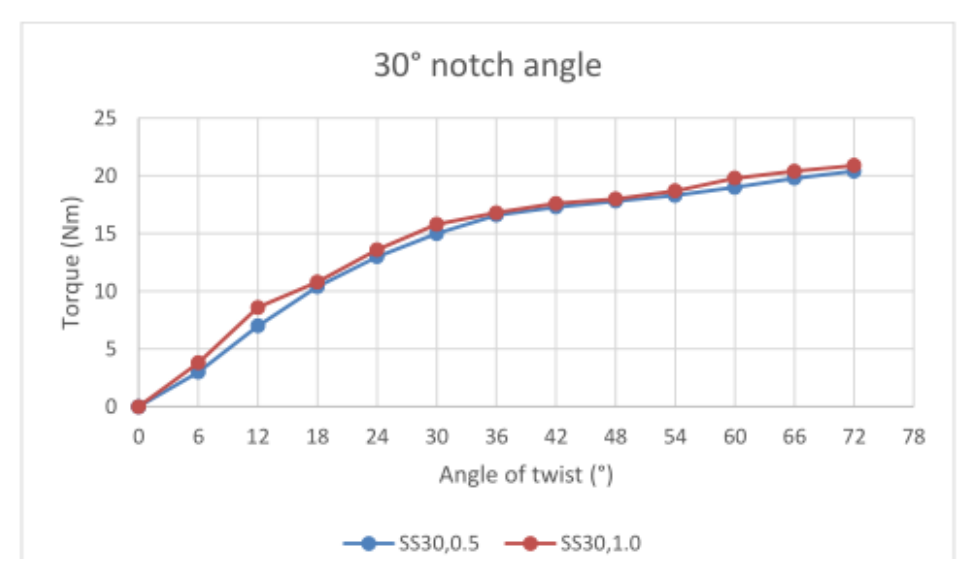

(a) Stainless steel at $30^{\circ}$ notch angle, $0.5 \mathrm{~mm}$ and $1.0 \mathrm{~mm}$ notch radius

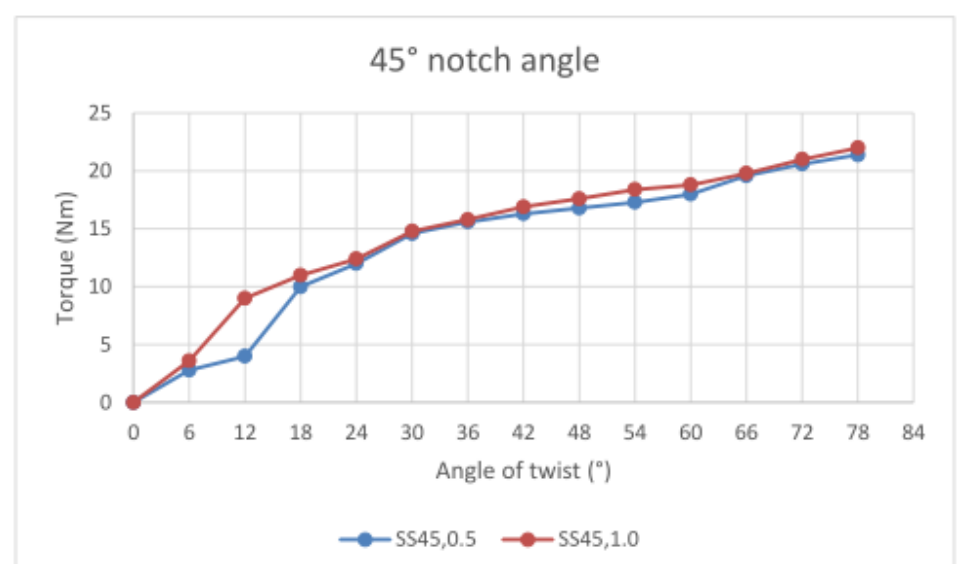

(b) Stainless steel at $45^{\circ}$ notch angle, $0.5 \mathrm{~mm}$ and $1.0 \mathrm{~mm}$ notch radius

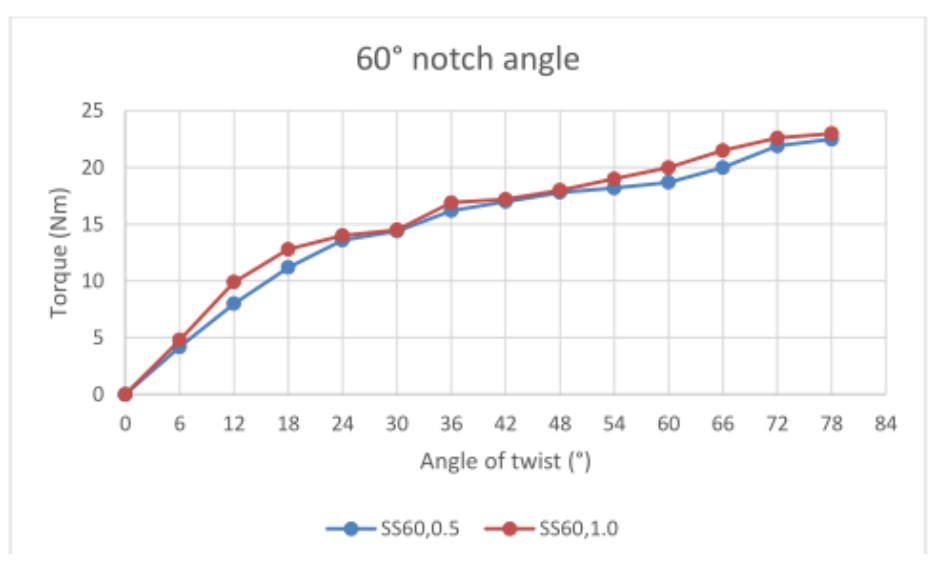

(c) Stainless steel at $60^{\circ}$ notch angle, $0.5 \mathrm{~mm}$ and $1.0 \mathrm{~mm}$ notch radius

\subsection{Impact Test}

Figure 6: Effect of notch parameters on AISI 302 steel (Stainless steel)

Tables 5 to 7 show the results of impact tests for the high carbon steel (HCS) and stainless steel (SS) workpiece samples. It can be observed from the tables (Tables 5 to 7) that the absorbed energy of the materials increase with increase in notch radius and notch angles for the two steels. It was also noticed that failure of the samples occurs at the notched point due to the impact loading, this occurs because of higher stress concentration at the notched point. Further observation in Table 5-7 shows that lower notch tips radius and smaller angles have the lowest absorption energy. This happens because the sample has smaller area at the root tip which makes it easier for crack to be initiated unlike that of larger tip radius and larger notch angle which the crack initiation has larger area to cover before it can 
be initiated hence resulting in higher absorbed energy. Carbon contents with respect to the AISI 1065 steel also plays a major role in the failure of the material because higher carbon contents is likely to increase the hardness of the material which make the material stronger and to absorbed more energy before failure.

Table 5: Absorption Energy at notch angle of $30^{\circ}$

\begin{tabular}{|c|c|c|}
\hline \multirow{2}{*}{ Notch tip radius (mm) } & \multicolumn{2}{|c|}{ Absorption Energy (Joules) } \\
\hline & AISI 1065 & AISI 304 \\
\hline 0.5 & 128 & 114 \\
\hline 1.0 & 162 & 119 \\
\hline \multicolumn{3}{|c|}{ Table 6: Absorption Energy at notch angle of $45^{\circ}$} \\
\hline \multirow{2}{*}{ Notch tip radius (mm) } & \multicolumn{2}{|c|}{ Absorption Energy (Joules) } \\
\hline & AISI 1065 & AISI 304 \\
\hline 0.5 & 162 & 122 \\
\hline 1.0 & 170 & 128 \\
\hline \multicolumn{3}{|c|}{ Table 7: Absorption Energy at notch angle of $60^{\circ}$} \\
\hline \multirow{2}{*}{ Notch tip radius (mm) } & \multicolumn{2}{|c|}{ Absorption Energy (Joules) } \\
\hline & AISI 1065 & AISI 304 \\
\hline 0.5 & 173 & 128 \\
\hline 1.0 & 178 & 132 \\
\hline
\end{tabular}

\section{CONCLUSIONS}

Investigation on the characteristics of notched AISI 1065 and AISI 304 steels with respect to tension, torsion and impact loading has been carried out, and based upon the findings from the experimental work the following conclusions can be drawn:

1. High notch tip radius of the samples improves the absorption energy of the steel samples.

2. Steel samples with bigger notch angle tend to have higher absorption energy under sudden load.

3. As the notch tip radius increases the sample show more resistance to twisting thus requiring more torque for twist to occur.

4. A high notch tip radius leads to higher ultimate tensile strength of the material before failure will occur.

\section{ACKNOWLEDGEMENT}

The authors would like to appreciate the following staff of the University of llorin for their assistance during the study. Mr. M. Ndagi of the department of Mechanical Engineering and Mr. Ibrahim Lateef, Central Workshop of the Faculty of Engineering.

\section{REFERENCES}

1. Callister Jr, W.D \& Rethwisch, D.G. (2012). Fundamentals of materials science and engineering: an integrated approach". John Wiley \& Sons.

2. Singh, R., Chauhan, S\& Gope, P.C. (2016). Influence of notch radius and strain rate on the mechanical properties and fracture behavior of TIC-welded 6061 aluminum alloy. Archives of Civil and Mechanical Engineering, 16(3), 513-523.

3. Antunes, F.V., Branco, R., Prates, P \& Costa, J.D. (2019). Fatigue crack growth in notched specimens: a numerical analysis. Frattura ed Integrità Strutturale, 13(48), 666-675.

4. Altenhof, W., Zamani, W.N., North, W \& Arnold, B. (2004). Dynamic stress concentrations for an axially loaded strut at discontinuities due to an elliptical hole or double circular notches. International Journal of Impact Engineering, 30(3). 255-274.

5. Majzoobi, G.H \& Daemi, N. (2010). The effects of notch geometry on fatigue life using notch sensitivity factor. Transactions of the Indian Institute of Metals, 63(2-3), 547-552

6. Eskandari, J., Abolghasemzadeh, M., Salavati, H \& Alizadeh, Y. (2014). The effect of notch tip position on the charpy impact energy for bainitic and martensitic functionally graded steels”. Materials Strength, 46(5), 700-716. Springer International Publishing AC. 
7. Sobieraj, M.C \& Rimnac, C.M. (2019). Fracture, fatigue, and notch behavior of PEEK”. In PEEK Biomaterials Handbook. William Andrew Publishing, 67-82.

8. Torabi, A.R \& Kamyab, M. (2019). The fictitious material concept. Engineering Fracture Mechanics, 209, 17-31.

9. Torabi, A.R \& Kamyab, M. (2019). Notch ductile failure with significant strain-hardening: The modified equivalent material concept. Fatigue \& Fracture of Engineering Materials \& Structures, 42(2), 439-453.

10. Charde, S.R., Ballal, A.R., Peshwe, D.R., Mathew, M.D and Paretkar, R.K. (2013). Effect of Notch on Creep Behavior of 316L(N) SS", 6th International Conference on Creep Fatigue and Creep-Fatigue Interaction [CF-6] Procedia Engineering vol. 55, 517-525. SciVerse

11. Gbadebo, O., Oluwamayowa, O., Oluwakayode, B., Adewale, O \& Horace, W. (2015). The effects of notch size and material microstructure on the notch sensitivity factor for notched components. Engineering Fracture Mechanics, 145, 181-196

12. Kobayashi, S. Ogou., S\& Tsurekawa., S. (2019). Grain boundary engineering for control of fatigue fracture in 316L austenitic stainless steel. Materials Transactions, 60(5), 623-630.

13. Naqiuddin., Z.M., Rahman, N.A., Jaini, Z.M \& Shamila, B.N. (2017). Effect of notch position on fracture energy for foamed concrete. In Materials Science and Engineering Conference Series 271(1), 012-019.

14. Nath, S.K \& Das, U.K. (2016). Effect of microstructure and notches on the fracture toughness of medium carbon steel. Journal of Naval Architecture and Marine Engineering, 3(1), 15-22.

15. Rittel, D., Rotbaum, Y., Rodríguez-Martínez, J.A., Sory, D \& Zaera, R. (2014). Dynamic necking of notched tensile bars: an experimental study. Experimental Mechanics, 54(6), 1099-1109.

16. Rozumek, D., Macha, A., Lazzarin, P \& Meneghetti, G. (2006). Influence of notch (tip) radius on fatigue crack growth rate. Journal of Theoretical and Applied Mechanics, 44, 127-137.

17. Tlilan, H.M., Sakai, N \& Majima, T. (2006). Effect of notch depth on strain-concentration factor of rectangular bars with a single-edge notch under pure bending". International Journal of Solids and Structures, 43(3-4), 459474.

18. Tlilan, H.M., Yousuke, S\& Tamotsu, M. (2005). Effect of notch depth on strain-concentration factor of notched cylindrical bars under static tension". European Journal of Mechanics-A/Solids, 24(3), 406-416.

19. Todkari, T.K., Swami, M.C \& Patil, P.S. (2015). Effect of notch angel on the fracture toughness of Al7075 T6 alloy-an experimental approach. IOSR Journal of Mech Civil Eng, 12(1), 1-5.

20. Zappalorto, M \& Lazzarin, P. (2011). Strain energy-based evaluations of plastic notch stress intensity factors at pointed V-notches under tension. Engineering Fracture Mechanics, 78(15), 2691-2706.

21. Zehsaz, M., Hassanifard, S \& Esmaeili, F. (2010). Fatigue life estimation for different notched specimens based on the volumetric approach. In EPJ Web of Conferences 6, (42001). EDP Sciences.

22. Zhao, Y., Peng, X., Huang, C., Fu, T., Yang, B., Hu, N \& Yan, C. (2019). Notch effects on deformation of crystalline and amorphous AIN-A nanoscale study. Ceramics International, 45(1), 907-917.

23. American Society for Testing and Materials (2016). Standard Test Methods for Tension Testing of Metallic Materials. West Conshohocken, PA, ASTM International.

24. American Society for Testing and Materials (2014). "Standard test method for Material Hardness. ASTM International.

25. American Society for Testing and Materials (2014). "Standard test methods for Impact Loading ASTM International. 